\title{
Coastal sea responses to atmospheric forcings at two different resolutions
}

\author{
Z. B. Klaić ${ }^{1}$, Z. Pasarić ${ }^{1}$, G. Beg Paklar ${ }^{2}$, and P. Oddo ${ }^{3}$ \\ ${ }^{1}$ Andrija Mohorovičić Geophysical Institute, Department of Geophysics, Faculty of Science, \\ University of Zagreb, Zagreb, Croatia \\ ${ }^{2}$ Institute of Oceanography and Fisheries, Split, Coratia \\ ${ }^{3}$ Istituto Nazionale di Geofisica e Vulcanologia, Bologna, Italy
}

Received: 9 March 2011 - Published in Ocean Sci. Discuss.: 12 April 2011

Revised: 20 July 2011 - Accepted: 10 August 2011 - Published: 31 August 2011

\begin{abstract}
We investigated coastal sea responses to three, multi-day strong wind episodes that occurred in the middle Adriatic during the Target Operational Period (TOP) of the European COastal sea OPerational observing and forecasting system (ECOOP) project. A high-resolution oceanographic model ( $1 \mathrm{~km}$ horizontal, $16 \sigma$ vertical layers) based on the modified Princeton Ocean Model (POM) was applied to a highly complex domain located in the coastal area of the eastern Adriatic Sea. The oceanographic model was nested into the Adriatic REGional model (AREG-2) covering the entire Adriatic Sea. Meteorological forcing was prepared by two atmospheric models. The coarser model was the European Centre for Medium-range Weather Forecast model (ECMWF, with horizontal and temporal resolutions of $0.25^{\circ}$ and $6 \mathrm{~h}$, respectively), and the finer one was the Aire Limitée Adaptation dynamique Développement InterNational model (ALADIN, with horizontal and temporal resolutions of $8 \mathrm{~km}$ and $3 \mathrm{~h}$, respectively, and winds dynamically adapted to a horizontal resolution of $2 \mathrm{~km}$ ). The results show that smallscale atmospheric features, which arise due to the orographically complex mainland and the number of islands and were not reproduced by the coarser atmospheric model, substantially affected surface currents, mass transports, sea surface temperature (SST) and surface salinity in the coastal area during strong Bora. For strong Sirocco, the atmospheric model's resolution was important for currents on the lee sides of islands.
\end{abstract}

Correspondence to: Z. B. Klaić (zklaic@gfz.hr)

\section{Introduction}

Because wind stress is the most important driving mechanism in the eastern Adriatic coastal area (Orlić et al., 1994), an accurate understanding of the wind structure over the Adriatic Sea is crucial for the understanding and the prediction of coastal circulation. Several modeling studies of the atmosphere over the Adriatic have stressed the importance of adequate model resolution for the realistic representation of meteorological fields over coastal regions that are surrounded by complex orography. It has also been argued that small-scale features of the meteorological fields are important when these fields are used as forcing in coastal ocean models (Signell et al., 2005; Pasarić et al., 2007, 2009; Zampato et al., 2007; Klaić et al., 2009b; Janeković et al., 2010). To our knowledge, apart from only a few investigations (Pullen et al., 2003; Signell et al., 2005; Zampato et al., 2007), there are no studies that quantitatively show the difference in the Adriatic Sea's response caused by atmospheric forcing at different resolutions, which was done in this study.

The question was initially addressed within the European COastal sea OPerational observing and forecasting system (ECOOP) project, namely within the task that aimed to improve the local capacity of non-EU countries to build operational coastal forecasting systems following ECOOP standards. Among other results, the operational oceanographic forecasts for the middle Adriatic coastal area have been issued every day for three days in advance. These forecasts have been provided for the six-month interval (i.e. Target Operational Period, hereafter TOP) extending from 1 February to 31 July 2009. In the present work, we scanned the TOP forecast period and selected multi-day episodes of strong

Published by Copernicus Publications on behalf of the European Geosciences Union. 
winds. These episodes were used to investigate the importance of the resolution of atmospheric forcing fields to the modeling of coastal ocean circulation and surface thermohaline properties.

Generally, there are two types of strong winds (with mean speeds of at least $10 \mathrm{~m} \mathrm{~s}^{-1}$ ) blowing over the Adriatic: Sirocco and Bora. Each can last for several days, and they are stronger and more frequent during the wintertime. While Sirocco blows along the basin, Bora has an acrossAdriatic direction; therefore, it is substantially influenced by the surrounding complex orography. Accordingly, Sirocco is usually considered to be a relatively simple event exhibiting large horizontal structures, whereas Bora is more complex and is characterized by small-scale spatial variability (e.g. Grubišić, 2004; Pasarić et al., 2009). However, Signell et al. (2005) showed that, for both Bora and Sirocco, different resolutions of atmospheric forcings can result in significant differences in the spatial and temporal structure of the Adriatic Sea's wave response. These results motivated us to inspect the differences in currents, sea surface temperatures (SST) and surface salinities modeled at fine $(2 \mathrm{~km}$ horizontal for winds and $8 \mathrm{~km}$ for other atmospheric variables with a temporal resolution of $3 \mathrm{~h})$ and coarse $\left(0.25^{\circ}\right.$ horizontal with a temporal resolution of $6 \mathrm{~h}$ ) resolutions of atmospheric forcing. Apart from quantifying these differences, we also compared the impacts that the atmospheric model resolution have on the Bora- and Sirocco-driven sea responses.

The present study differs from previous investigations in several respects. Whereas Pullen et al. (2003) addressed the long-term statistics of modeled currents at the northern Adriatic, we looked at the modeled currents and surface thermohaline characteristics of the eastern coastal regions of the middle Adriatic during specific high wind conditions. Signell et al. (2005) and Zampato et al. (2007) examined the entire Adriatic Sea, but they focused on wave modeling and sea level forecasting, respectively.

This manuscript is organized as follows. Section 2 provides a description of the ocean model and the atmospheric data used. The investigated episodes are described in Sect. 3. The results of these investigations are discussed in Sect. 4. Finally, Sect. 5 presents our conclusions.

\section{Oceanographic modeling system}

\subsection{Oceanographic model}

The oceanographic modeling system simulating temperature, salinity, currents and surface elevation is based on the modified Princeton Ocean Model (POM) (Blumberg and Mellor, 1987). The POM model is three-dimensional and non-linear with complete thermo- and hydrodynamics and allows the possibility to include air-sea interactions and forcing from rivers. The modified model is called ASHELF-2, and it is described in detail in Orlić et al. (2006). ASHELF-2 is a high-

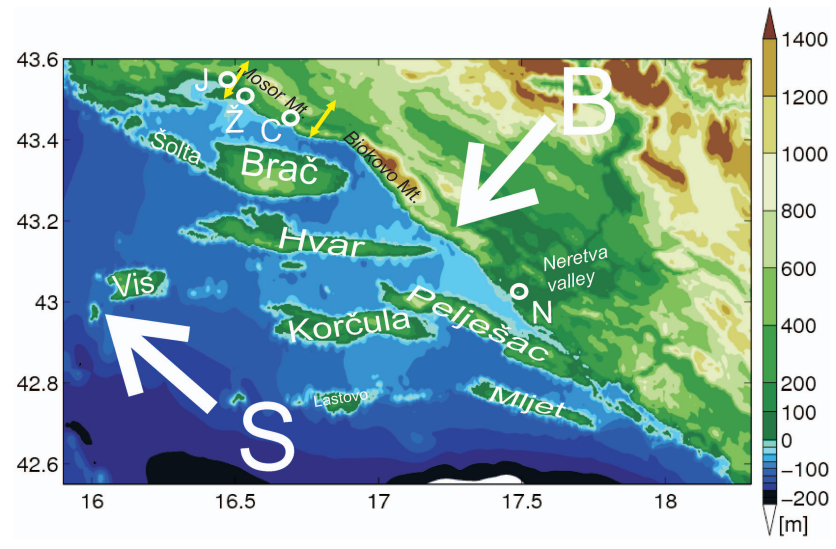

Fig. 1. Modeling domain and the actual topography. Positions of the two mountain passes (one northwest and the other southeast of Mosor Mountain) are indicated in yellow. The white circles show river estuaries for Jadro (J), Žrnovnica $(\check{Z})$, Cetina (C) and Nertva $(\mathrm{N})$. Large white arrows indicate general Bora (B) and Sirocco $(\mathrm{S})$ wind directions.

resolution ( $1 \mathrm{~km}$ horizontal with $16 \sigma$ layers) ocean model currently designed for the middle Adriatic eastern coastal area $\left(15.9^{\circ} \mathrm{E}, 42.6^{\circ} \mathrm{N}, 18.3^{\circ} \mathrm{E}, 43.6^{\circ} \mathrm{N}\right)$ (Fig. 1). The modeling domain is highly complex; the coastline is irregularly shaped and there are a number of islands, islets and cliffs in the area. In addition, adjacent to the sea, the edge of the Dinaric Alps containing the Mosor and Biokovo mountains stretches parallel to the along-basin axis of the Adriatic Sea.

The ASHELF-2 model was forced with surface momentum and buoyancy fluxes and discharges from the four major rivers of the area, which are the Jadro, Žrnovnica, Cetina and Nertva rivers. Surface fluxes were interactively computed using atmospheric fields, which were obtained by the two models described in Sect. 2.2, and sea surface temperature from ASHELF-2 using standard bulk formulae as described in Orlić et al. (2006). The drag coefficient used in the wind stress computation was obtained according to Hellerman and Rosenstein (1983), whereas heat flux components were obtained using standard bulk formulas. The Reed (1977) formula was used for solar radiation, longwave flux was calculated according to May (1986) and the sensible and latent heat fluxes were obtained following Kondo (1975). To calculate buoyancy fluxes, we used the interactively calculated evaporative flux together with precipitation from atmospheric models and climatological monthly discharges of the four rivers (Pasarić, 2004; Orlić et al., 2006). The rivers were included in the surface buoyancy flux at the grid points that correspond to the location of their mouths. Jadro, Žrnovnica and Cetina were considered to be point sources, whereas Neretva was assumed to be the line source occupying six grid points. Initial and lateral open boundary conditions for the ASHELF-2 were provided by the Adriatic REGional model (AREG-2), which covers the entire Adriatic Sea (Oddo et 
Table 1. List of investigated strong wind episodes. MM and MG correspond to maximum hourly wind speed and maximum wind gust as reported by DHMZ (2009). I is the code of the time interval characterized by persistent airflow, where its persistence is assessed from the modeled wind fields.

\begin{tabular}{lcccc}
\hline $\begin{array}{l}\text { Description according to } \\
\begin{array}{l}\text { MHS Bulletins } \\
\text { (DHMZ, 2009) }\end{array}\end{array}$ & $\begin{array}{c}\text { MM } \\
\left(\mathrm{m} \mathrm{s}^{-1}\right)\end{array}$ & $\begin{array}{c}\text { MG } \\
\left(\mathrm{m} \mathrm{s}^{-1}\right)\end{array}$ & $\begin{array}{c}\text { Duration of persistent airflow } \\
\text { conditions }\end{array}$ & I \\
\hline $\begin{array}{l}\text { Moderate to strong Bora } \\
\text { Stormy Bora, snow at }\end{array}$ & 22.2 & 38.9 & 12 Feb, 00:00:00-16 Feb, 00:00:00 & B1 \\
$\begin{array}{l}\text { islands, Split airport closed } \\
\text { Stormy Sirocco }\end{array}$ & 27.8 & 41.7 & 18 Feb, 12:00:00-20 Feb, 00:00:00 & B2 \\
\hline
\end{tabular}

al., 2006; Chiggiato and Oddo, 2008). AREG-2, which has a horizontal resolution of approximately $2 \mathrm{~km}$ and 31 vertical $\sigma$ layers, has been operational since April 2003 and provides nine days of forecast on a daily basis in addition to the previous week's analyses. ASHELF-2 is initialized using the corresponding AREG-2 fields of temperature, salinity and velocity at the beginning of each studied wind episode. To include the influence of the adjacent area on the local coastal dynamic, the ASHELF-2 model was nested into AREG-2 using a simple, off-line, one-way nesting technique ( $\mathrm{Za}-$ vatarelli and Pinardi, 2003). Time varying daily averages of the velocity, temperature, salinity and surface elevation from the AREG operational products were interpolated on the ASHELF-2 open boundaries. The open boundary values were also linearly interpolated in the time between the daily averages during the simulations and corrected to ensure that the volume transport across the ASHELF-2 open boundaries matched the volume transport across the corresponding AREG-2 section (according to Pinardi et al., 2003). During the TOP period, the forecasted AREG fields were interpolated on the ASHELF-2 open boundaries, whereas here, we used AREG hindcasted fields in the simulations of the selected wind periods.

\subsection{Atmospheric forcing}

Atmospheric forcing was produced using two models, the European Centre for Medium-range Weather Forecast (ECMWF) model, and the Aire Limitée Adaptation dynamique Développement InterNational model (ALADIN) (Geleyn et al., 1992). In the first case, the ECMWF analyses fields had horizontal and temporal resolutions of $0.25^{\circ}$ and $6 \mathrm{~h}$, respectively. In the second case, we used the hydrostatic version of the limited area model ALADIN that was implemented to the Croatian domain.

Physical parameterizations in the ECMWF model are described in full details at the model web site http://www. ecmwf.int/research/ifsdocs/CY28r1/Physics/Physics-04-01. html\#wp963903, and they are almost the same as those used by ALADIN (http://www.cnrm.meteo.fr/aladin/spip.php? page=sommaire, Geleyn et al., 1992). Boundary conditions for the ALADIN model are incorporated by relaxation method applied within the so called coupling boundary zone (Radnóti, 1995).

ALADIN was run twice per day (at 00:00 and 12:00 UTC) at the Croatian Meteorological and Hydrological Service, and the output fields were available at horizontal and temporal resolutions of $8 \mathrm{~km}$ and $3 \mathrm{~h}$, respectively. The initial and boundary conditions for the ALADIN runs were provided by the analysis and forecast of the Action de Recherche Petite Echelle Grande Echelle (ARPEGE) global model, which was run in Météo-France. In addition, a high-resolution dynamic adaptation was also run to obtain the fine scale wind fields at a horizontal resolution of $2 \mathrm{~km}$ (Ivatek-Šahdan and Tudor, 2004).

\section{Investigated episodes}

According to the Bulletins of the Meteorological and Hydrological Service of Croatia (hereafter MHS) (DHMZ, 2009), three multi-day episodes of strong winds occurred over the modeling domain during the TOP. Two of them corresponded to Bora flows, and one corresponded to Sirocco flow. Both winds are well known due to their major roles in the forcing of the Adriatic Sea (e.g. Orlić et al., 1994; Pasarić and Orlić, 2004; Beg Paklar et al., 2001, 2005; Ferrarese et al., 2009; Klaić et al., 2009a). For each of these strongwind episodes, we identified a time interval during which the modeled airflow conditions over the entire modeling domain were persistent and nearly stationary. These intervals were denoted by B1, B2 and S, respectively (Table 1), where $\mathrm{B}$ and $\mathrm{S}$ corresponded to the Bora and Sirocco flows, respectively. Inspection of the surface analyses charts of the MetOffice (http://www.wetter3.de/fax, not shown here) corroborated the existence of synoptic-scale pressure fields that favor the establishment of the above-mentioned Bora and Sirocco airflows. Namely, it is well known that Bora goes along with the synoptic-scale southward air-pressure gradient accompanied with the cold air outbreaks from the north 
(e.g. Bajić, 1987); while Sirocco, which is above the Adriatic warm and humid, is related to the northwestward or northward synoptic-scale air pressure gradient (e.g. Jurčec et al., 1996). Such gradients can be attained by several different synoptic setups, depending on relative positions of high- and low-pressure synoptic scale disturbances. Typical synopticscale pressure field patterns for Bora and Sirocco are depicted in climatological study of Heimann (2001).

\section{Results and discussion}

\subsection{Bora}

Because the key features in the modeled fields for both Bora episodes were similar, here, we only show the results for the stronger episode (B2 in Table 1). Due to wind field persistence, wind field patterns for individual time instances during the investigated episodes were very similar to those seen in mean fields, which were obtained by averaging over a corresponding time interval (not shown here). Therefore, we discuss only the mean-modeled fields. Figure 2 shows the averaged ALADIN- and ECMWF-modeled pseudo-stresses, in addition to the difference between the two. The pseudostress was calculated by multiplying each wind vector with its magnitude. Although our oceanographic modeling system employs wind stress, here, we show the pseudo-stress to keep the information on the wind field (more precisely, on the wind kinetic energy) above the ground. We note however, that both pseudo-stress and bulk formulae calculated stress exhibit very similar spatial patterns (not shown here). Although the ECMWF model results in an almost homogenous wind field, and consequently, a homogenous pseudo-stress field over the entire domain (with values gradually increasing offshore due to weaker surface friction), the ALADIN wind and pseudo-stress fields exhibit fine structures. Based on climatological (Orlić et al., 1994), field measurement (Grubišić, 2004) and modeling (Klaić et al., 2003; Belušić and Klaić, 2006) meteorological studies of Bora flow, we can expect topographically induced jets downstream of mountain passes. In our case, these were found downstream of two passes shown in Fig. 1; one pass was northwest and the other southeast of Mosor Mountain. Additionally, according to the ALADIN results, pseudo-stress during Bora strengthens in two regions above the open sea. One region was found in the southwestern part of the domain, and the other was downwind of the line stretching from the eastern tip of Korčula to Mljet Island. The wind strengthening above the open sea agrees well with other Bora studies for the northern Adriatic (Makjanić, 1970, 1976; Klaić et al., 2003), which showed that winds are higher over the sea (i.e. farther from the coastal barrier) than on the coast itself. This trend can be attributed to weaker friction. However, we note that, in these two regions, the airflow and consequently the pseudo-stress is additionally amplified due to the upstream blocking and splitting

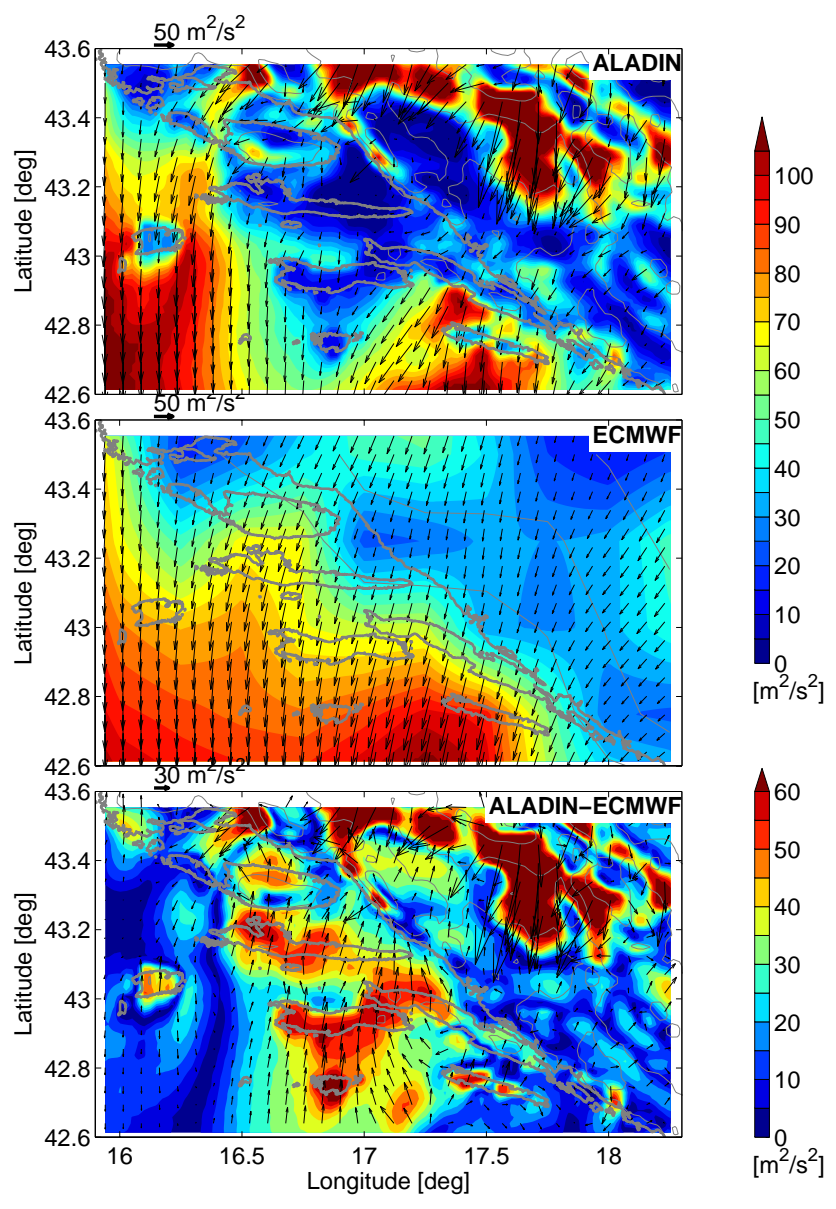

Fig. 2. Mean ALADIN (top panel) and ECMWF (center panel) modeled wind pseudo-stress for the B2 Bora episode (Table 1). The bottom panel shows the difference between these two. Additionally, the magnitudes of vector differences |ALADIN-ECMWF| are shown in colors. Topography contours, as seen from the models, and shore lines are indicated with thin and thick grey lines, respectively.

of the Bora flow that occurs above the mainland. Namely, strong winds, which are found in the northeastern part of the domain, hit Biokovo Mountain and adjacent obstacles and split into two branches. Both branches are maintained further downstream by the topographies of the islands. The western branch amplifies while passing through the southeastern mountain pass, hits the northern coast of Brač and then mainly turns westward. Upstream of the passage between Brač and Šolta, the flow meets the southwestward jet emerging from northwestern mountain pass and further strengthens. Downstream of Šolta, the western branch is south-southwestward. The eastern branch is very strong over the northern part of the Neretva valley, and it gradually weakens when approaching the coastline. After passing above the central part of Pelješac Peninsula, this southwestward branch strengthens again. 
Above the sea, the differences between ALADIN and ECMWF wind pseudo-stress (Fig. 2, bottom panel) are most pronounced within the along-Bora oriented funnel-shaped region that stretches from the coast, passes across Hvar, western Pelješac, Korčula and Lastovo, and continues further downstream. This funnel-shaped region coincides with several ALADIN modeled wakes induced by coastal mountains and islands (not shown here), which are accompanied by low values of pseudo-stress (Fig. 2, top panel) and are not captured by the ECMWF model (Fig. 2, center panel).

Figure 3 shows the modeled mean surface currents obtained using the two atmospheric forcings and the difference field. We can see the effects of the eastward, AREG2-modeled currents at the western boundary for both atmospheric forcings. The eastward flow is a part of a small cyclonic gyre obtained by AREG in the area near the western ASHELF-2 open boundary.

For the ALADIN forcing, the most prominent feature is a strong northwestward current (over $0.4 \mathrm{~m} \mathrm{~s}^{-1}$ ) in the Brač channel between the island and the mainland (latitudes roughly from 43.3 to $43.45^{\circ} \mathrm{N}$ ). Conversely, for the ECMWF forcing, this westward flow component is substantially weaker. Accordingly, this Brač channel current is also the most noticeable of the differences between the two cases (Fig. 3, bottom panel). We believe that this prominent along-shore current is partly supported by a small, anticyclonic eddy found north of Pelješac (Fig. 3, top panel) due to the wind curl in the area. The eddy, which was even more pronounced in episode B1 (not shown here), reaches the straight between the Hvar island and mainland supporting the alongshore currents towards the northwest. In contrast, for the ECMWF forced currents, an almost homogenous wind field pushes the surface waters towards the northern coast of Pelješac to produce a westward surface current in this area. Therefore, in this case, there is no surface northwestward current along the mainland. Similarly, a small anticyclonic eddy (although with substantially weaker currents), which is caused by the eastern branch of the airflow split due to the blocking by Biokovo Mountain, is also found north of eastern Hvar. Because none of these eddies were found in the results obtained by ECMWF forcing, we believe that their genesis is completely driven by the atmospheric forcings. The positions of both eddies are also clearly seen in the differences field (Fig. 3, bottom panel).

Another noticeable result for ALADIN forcing is an alongBora, funnel-shaped region of weaker surface currents that coincides with the funnel-shaped region of weaker winds (Figs. 2 and 3, top panels). While the airflow in this region is southwestward or south-southwestward, in the sea, the westward component is more pronounced. Therefore, the relatively weak surface currents are mainly west-southwestward or southwestward. Obviously, this turning of the surface currents towards the west with respect to the airflow arises due to the channeling effects of mainly east-west oriented islands. Similar to the airflow field, to the west and east of this funnel-

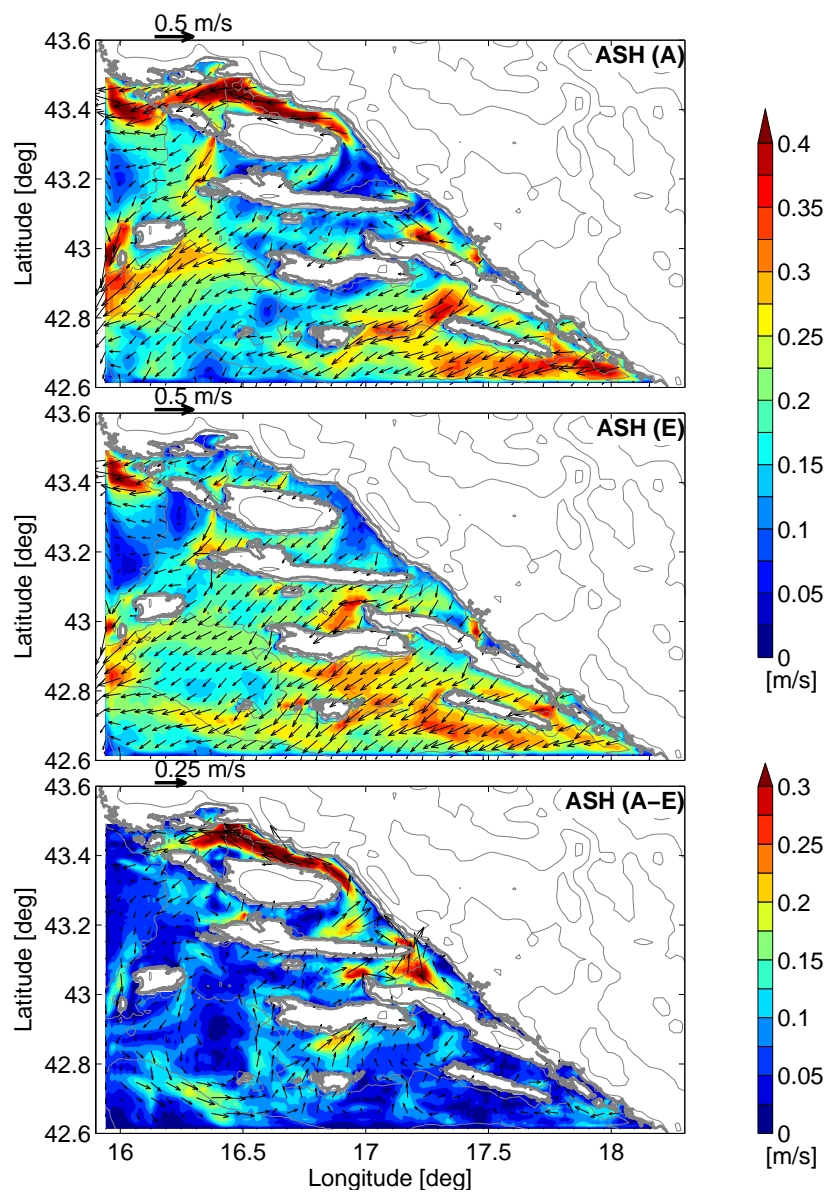

Fig. 3. The ASHELF-2 modeled mean surface currents for the B2 Bora period (Table 1) obtained by ALADIN and ECMWF forcing (top and center panels, respectively) and the differences between these two. Additionally, the magnitudes of vector differences |ALADIN-ECMWF| are shown in colors.

shaped region, we found strong surface currents (which are maintained by the two strong airflow branches originating from the flow splitting above the mainland). Again, compared to the airflow directions, these currents turn toward the west due to the orientation of the islands.

Finally, for both atmospheric forcings and for both Bora episodes (B1 and B2 in Table 1), we found a flow splitting of this westward, surface current in the Brač channel. One branch proceeds westward through the channel between the mainland and Šolta Island, and the other turns southward and persists through the strait between Šolta and Brač with substantially stronger currents in the case of the ALADIN forcing.

In the open sea, outside of the island area, both atmospheric forcings produced similar southwestward currents.

Several prominent features were found in the vertically averaged currents obtained by the ALADIN forcing (Fig. 4, top panel). One of these is the northwestward, along-shore mass transport in the channel between the Brač and Šolta islands 
and the mainland, which was already found in the surface currents. This transport stretches toward the northwestern edge of the domain, where it is further strengthened by the convergence of the northeastward and northwestward currents found roughly at latitudes between 43 and $43.5^{\circ} \mathrm{N}$ and longitudes between 15.9 and $16.4^{\circ} \mathrm{E}$.

Additionally, several eddies were found. The first is a small, anticyclonic eddy between the mainland and Pelješac (which was also already found in the surface currents). The second is an anticyclonic eddy to the south of Šolta, whose western part supports the convergence of above-mentioned currents and the consequent strengthening of the along-shore mass transport at the very northwestern edge of the domain. The third is a cyclonic eddy in the southwestern part of the domain (centered around $42.9^{\circ} \mathrm{N}$ and $16.4^{\circ} \mathrm{E}$ ), which is in accordance with the wind curl caused by a strong eastward wind shear (Fig. 2, top panel) and coincides with the surface currents eddy (Fig. 3, top panel). The second and third eddies were also found for the ECMWF forcing (Fig. 4, center panel), and the most pronounced difference between the two forcings was found in the channel between the mainland and Brač and Šolta islands (Fig. 4, bottom panel).

Spatial structures of the latent and sensible heat fluxes reproduced using either ALADIN or ECMWF outputs are very similar and are primarily influenced by the wind stress and air temperature variability (Fig. 5). Due to the similarity of these heat flux components Fig. 5 depicts only the latent flux from both atmospheric models together with air temperature fields. On the other hand, significant differences in the both heat flux components arise between model runs using different atmospheric forcings. As the air temperatures simulated with ALADIN are higher than those from ECMWF over almost entire domain, with maximum differences of about $3{ }^{\circ} \mathrm{C}$ (Fig. 5, top panel), both latent and sensible heat fluxes result in the stronger cooling in the case of ECMWF forcing. Moreover, spatial variations in the ALADIN air temperatures are influenced by the presence of the islands, while ECMWF model is completely missing this effect.

Figure 6 shows modeled SST and salinities for the two forcings. Figure 5 indicates the lowest cooling due to both latent and sensible heat flux is in the funnel-shaped area coinciding with low wind stress reproduced by the ALADIN model. This is also the area with the highest differences between heat flux components from two atmospheric models (Fig. 5, bottom right panel) and the area with the highest differences of $1{ }^{\circ} \mathrm{C}$ between SST calculated using ECMWF and ALADIN outputs (Fig. 6, third row, left panel). Because the satellite-measured SST of the investigated area for the B2 episode was not available, we show the satellite SST for the day after the episode. The satellite-measured SST varied from $11-12.5^{\circ} \mathrm{C}$ (along the mainland coastal areas) to 14-14. $5^{\circ} \mathrm{C}$ (southwestern part of the domain), and the corresponding ALADIN-forced values ranged from $10-11.5^{\circ} \mathrm{C}$ to $13-13.5^{\circ} \mathrm{C}$. Again, the ALADIN-forced field SST exhibited more complex patterns than the ECMWF-forced SST.

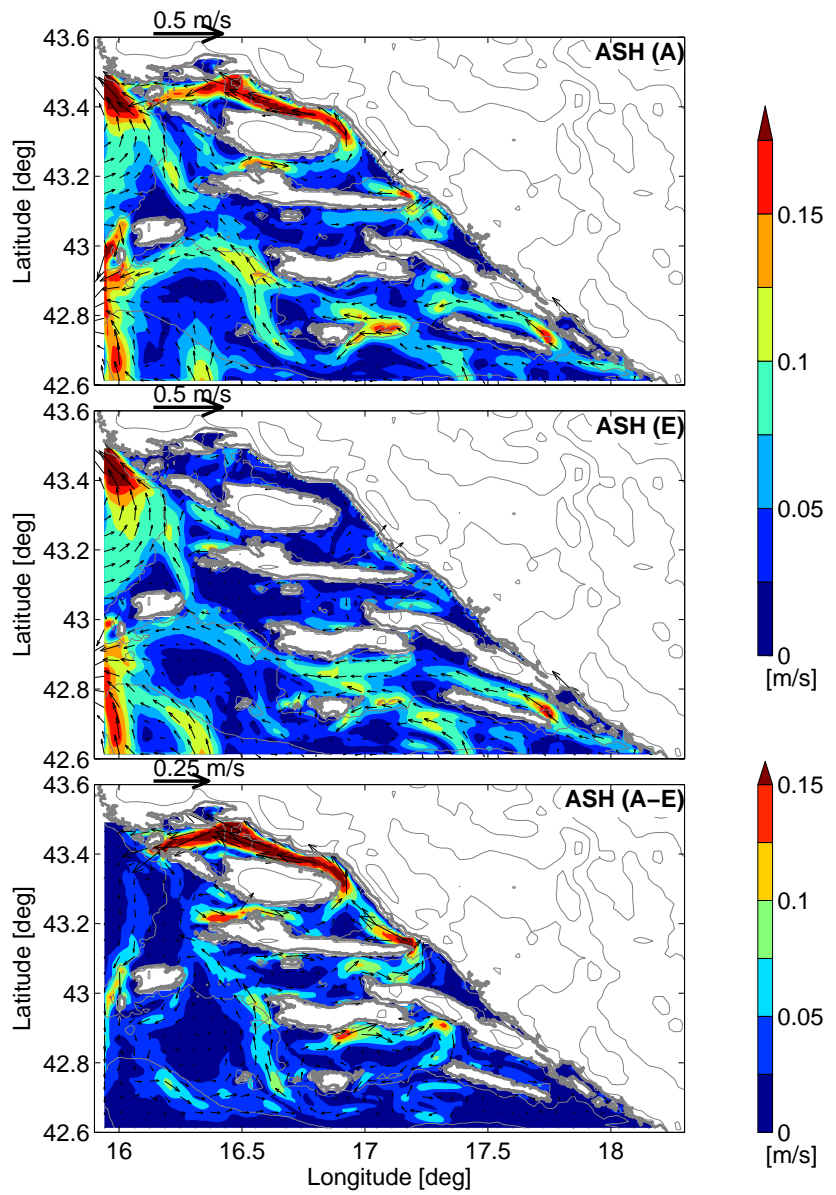

Fig. 4. Mean ASHELF-2 modeled vertically averaged currents for the B2 Bora period (Table 1) obtained with ALADIN and ECMWF forcing (top and center panels, respectively) and the differences between these two (bottom panel). Additionally, the magnitudes of vector differences $\mid$ ALADIN-ECMWF $\mid$ are shown in colors.

The differences between the two experimental outcomes varied from $-0.75^{\circ} \mathrm{C}$ (corresponding to the warmer ECMWFforced SST) to $1.25^{\circ} \mathrm{C}$ (warmer ALADIN-forced SST). The former is most clearly seen in triangle-shaped region north of eastern Hvar, whereas the latter is the most prominent in three areas: north of Šolta, south of western Hvar and west of Korčula. The most pronounced discrepancies between the two forcing outcomes mainly coincide with the funnelshaped region of weak winds (i.e. the weak pseudo-stress in Fig. 2, top panel) and the resulting weak surface currents (Fig. 3, top panel) with an exception north of Šolta, where the strong winds and currents are accompanied by large differences in the ALADIN- and ECMWF-forced SST.

Despite a general bias affecting the results of both of the model simulations, the satellite-derived SST is in good agreement with the corresponding field obtained by forcing the model with the ALADIN fields. Both of the datasets agree (ALADIN forced model and satellite), showing a mostly homogenous SST between the islands (north of $42.8^{\circ}$ ) and the 

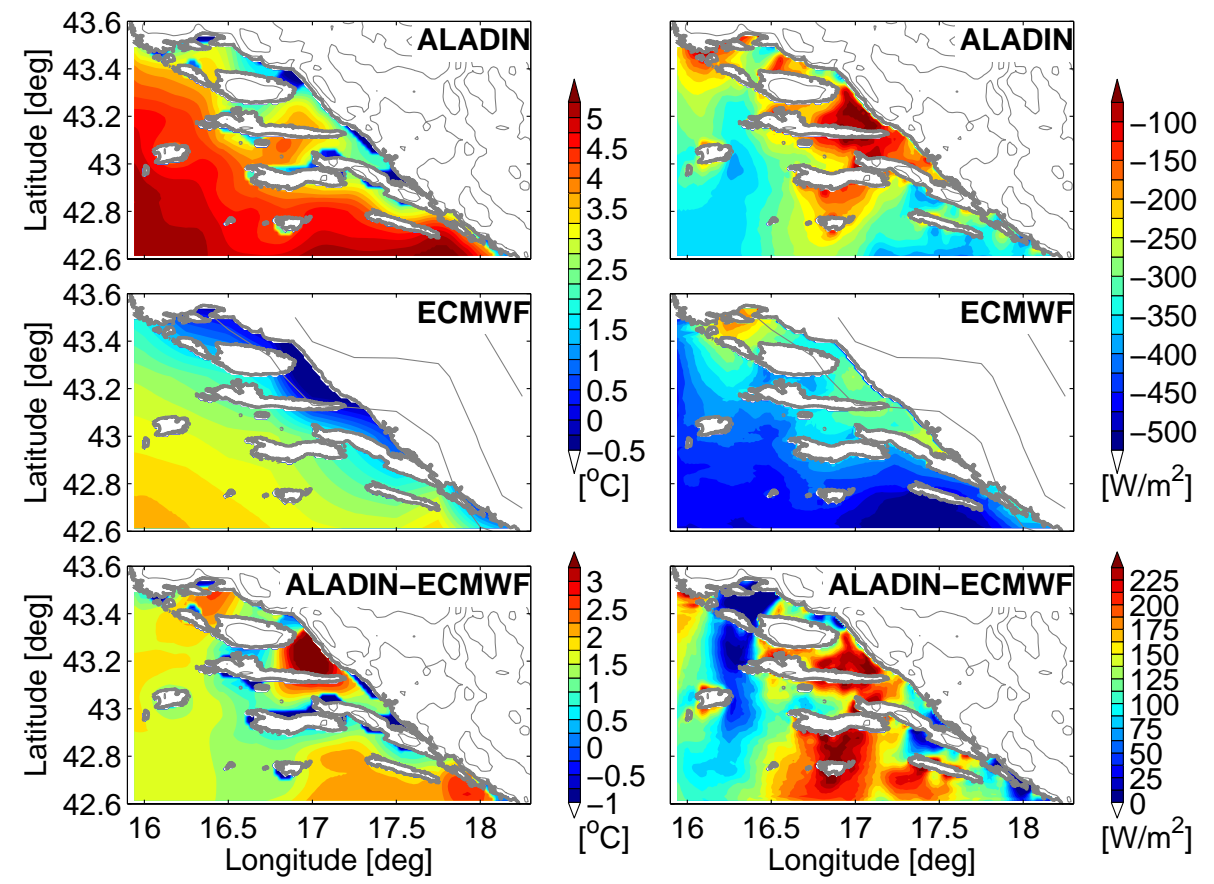

Fig. 5. Mean ALADIN (top panels) and ECMWF (center panels) modeled air-temperature (left panels) and latent heat flux (right panels) for the B2 Bora episode (Table 1). The bottom panels show the differences between respective fields above.

coast and a strong horizontal gradient that separates the cold coastal waters from the warmer off-shore ocean. On the contrary, the ECMWF-driven SST is characterized by a noticeable colder area south of the Islands Brač Hvar and Korčula and a weaker horizontal gradient. Lower SST south of the main islands is a consequence of the stronger cooling due to sensible and latent heat fluxes in case of the ECMWF forcing (Fig. 5).

Over the open sea, the ALADIN-forced surface salinity is higher than the corresponding ECMWF values (Fig. 6, right panels). Conversely, north of Pelješac and eastern Hvar, lowsalinity water spreads due to the northwestward current between Pelješac and eastern Hvar and the westward current along northern coast of eastern Hvar. However, the ECMWF forcing resulted in significantly higher surface salinities in the same area with low salinities occupying a narrow band along the northern Pelješac coast. Higher salinities along the mainland coast that were obtained by ECMWF forcing resulted from strong evaporation in the area (Fig. 5 - latent heat flux). Generally, discrepancies between the two forcing outcomes varied from $-0.875 \mathrm{psu}$ (corresponding to higher ECMWF-forced than ALADIN-forced salinities) to over $0.500 \mathrm{psu}$ (higher ALADIN-forced values). Finally, the pattern of salinity differences is very similar to the pattern of sea surface temperature differences, which point to the dominant impact of wind on both the temperature and salinity distributions.

\subsection{Sirocco}

Figure 7 shows modeled mean pseudo-stress fields during the investigated Sirocco episode (Table 1). Generally, over the sea, the ECMWF-modeled Sirocco pseudo-stress is somewhat stronger than the corresponding ALADIN field. In contrast to Bora, the ALADIN and ECMWF patterns above the open sea are similar. In both cases, the winds blow in a nearly constant northwestward direction. Because the wind gradients are small, a very weak wind curl is found in this region. Approaching the mainland, the ECMWF-modeled pseudostress gradually decreases because the model does not resolve any of the islands, and along the coast, it "sees" rather flat topography. On the contrary, the ALADIN-modeled field in the coastal area exhibits considerable variability. Pseudostress weakens over the islands and strengthens after passing them. This result is most clearly seen if a fetch at the lee side of the island is sufficiently large (e.g. north of Korčula and north of the eastern part of Hvar). Therefore, the differences between the ALADIN and ECMWF fields above the sea were found in between islands, especially in the east-west elongated channels, where the ALADIN model succeeded in reproducing some of the channeling effects.

Figure 8 depicts vertically averaged mean currents for two atmospheric forcings and the difference between the two. In the open sea, vertically averaged currents for both forcings are very similar, and they follow the airflow. Both forcings 

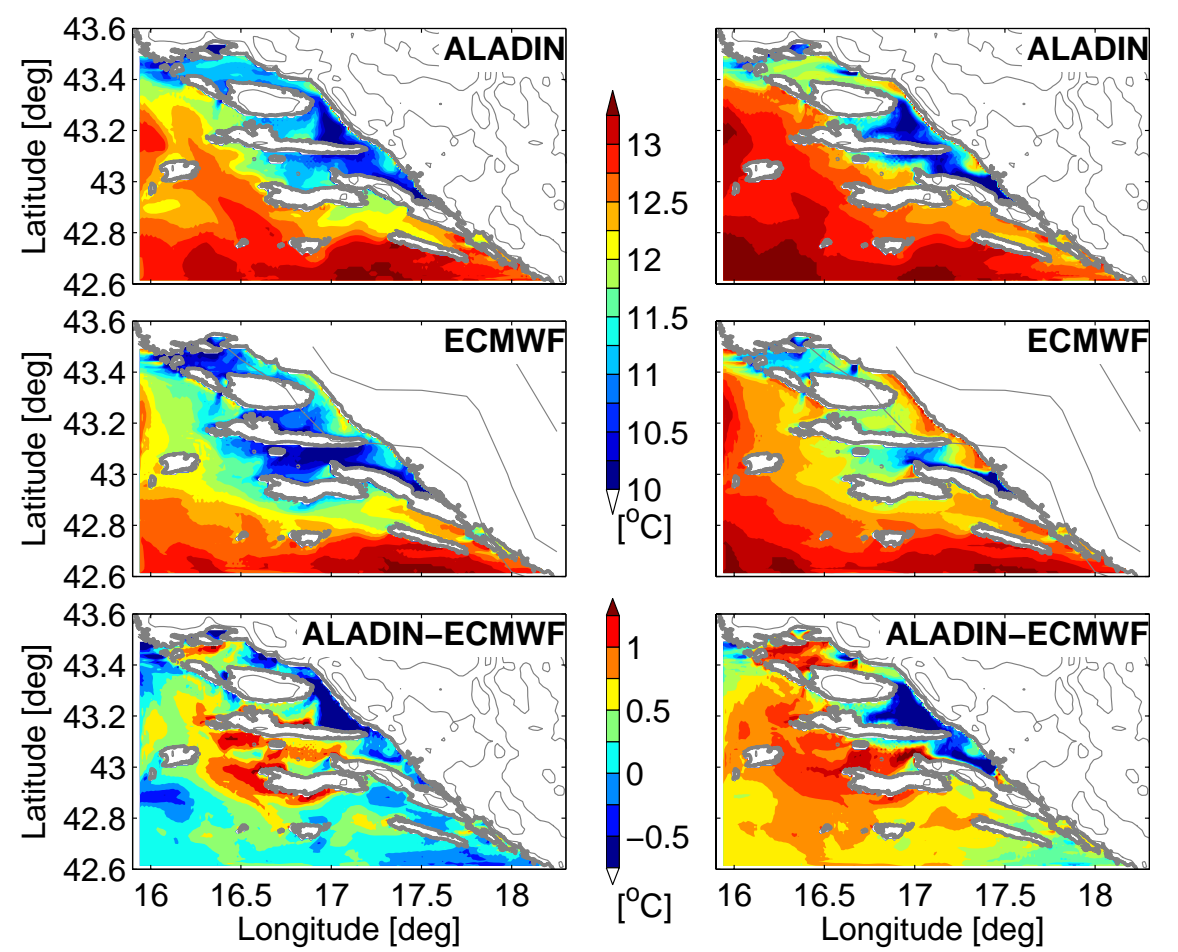

38.25

38

$-37.75$

37.5

37.25

37

36.75

[psu]
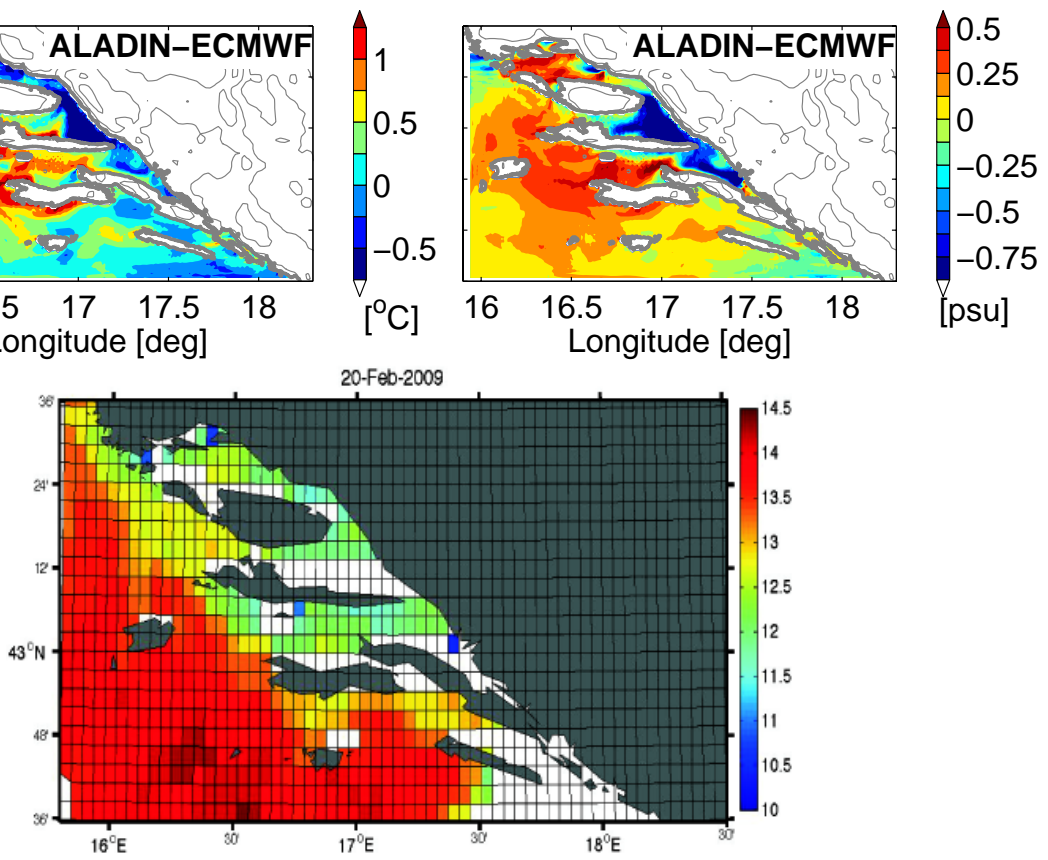

Fig. 6. Mean ASHELF-2 modeled sea surface temperatures (left panels) and surface salinities (right panels) for the B2 Bora period (Table 1) obtained by ALADIN and ECMWF forcing (upper two rows) and the differences between these two (third row). The lowermost panel shows the satellite-measured sea surface temperature for 20 February 2009.

result in very similar current splitting by distant islands (Lastovo and Vis), similar wakes and consequent flow convergences downstream of these islands.

Due to the more uniform wind field, the ECMWF-forced, vertically averaged currents in the coastal areas and in the channels between islands closer to the mainland are much more uniform than the ALADIN forced currents. Therefore, the differences between the two cases, which arise mainly due to the complexity of ALADIN winds and the resulting complex wind stress in coastal areas, are the most pronounced on the lee sides of the islands. The most noticeable is in the Brač channel to the north of the western part of the island, which has differences between the two cases of up to approximately $0.15 \mathrm{~m} \mathrm{~s}^{-1}$ (Fig. 8, bottom panel). Finally, for both forcings, a strong downwind jet intensifies along the southern coast of Korčula and the strait between Hvar and Vis.

Similar results were also obtained for the mean surface currents (not shown). For both forcings, the mean surface currents for the open sea are similar, and they resemble the vertically averaged mean currents. Additionally, ECMWFforced surface currents are somewhat stronger, which is in accordance with generally stronger ECMWF stress over the area compared to the ALADIN winds. Differences between the two forcings are the most pronounced on the lee sides of islands with maximum values (up to approximately $0.2 \mathrm{~m} \mathrm{~s}^{-1}$ ), which were found in the along-coast stripe stretching northwestward from the eastern tip of Hvar towards the western tip of Šolta. Here, the ALADIN-modeled surface currents range from 0.4 to $0.6 \mathrm{~m} \mathrm{~s}^{-1}$. 


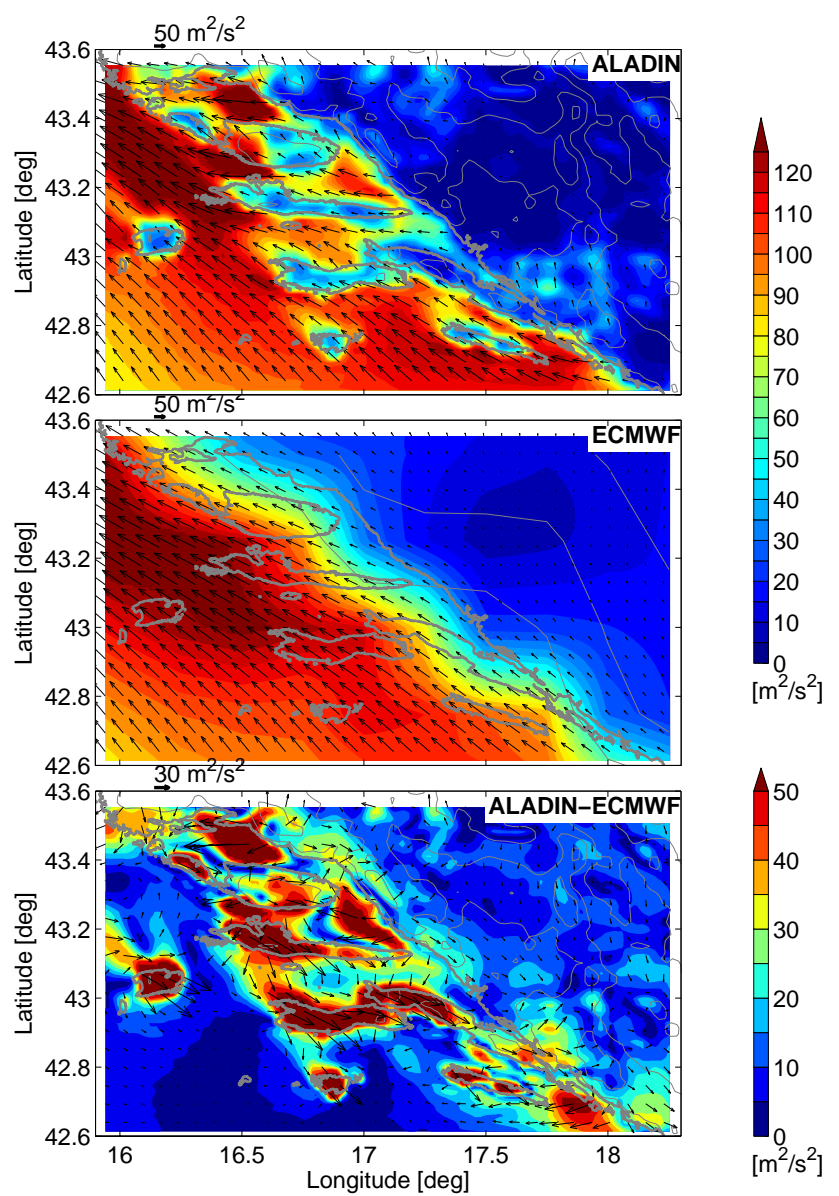

Fig. 7. Mean ALADIN (top panel) and ECMWF (center panel) modeled pseudo-stress for the Sirocco episode (Table 1). The bottom panel shows the difference between these two. Topography contours, as seen from the models, and shore lines are indicated by thin and thick gray lines, respectively.

Finally, Fig. 9 depicts the modeled SST and salinities for both forcings. Despite of the discrepancies in the latent and sensible heat fluxes calculated using ECMWF and ALADIN outputs, which arise from lower air temperatures reproduced by ALADIN over almost entire domain (not shown here), both forcings gave very similar SST fields (Fig. 9, left panel), and they agree reasonably well with the satellite-measured SST (Fig. 9, bottom panel). The differences between SST modeled with ALADIN and ECMWF outputs are close to the accuracy of the satellite measurements and therefore it is hard to conclude which thermal forcing is better in the case of Sirocco wind.

Discrepancies between the two experiments varied from $-0.25^{\circ} \mathrm{C}$ (higher ECMWF-forced SST) to $0.37^{\circ} \mathrm{C}$ (higher ALADIN-forced SST). A slightly higher ECMWF-forced SST than the ALADIN-forced SST is most clearly seen on the windy side of Korčula Island. On the contrary, a somewhat higher ALADIN-forced SST was found at the lee sides

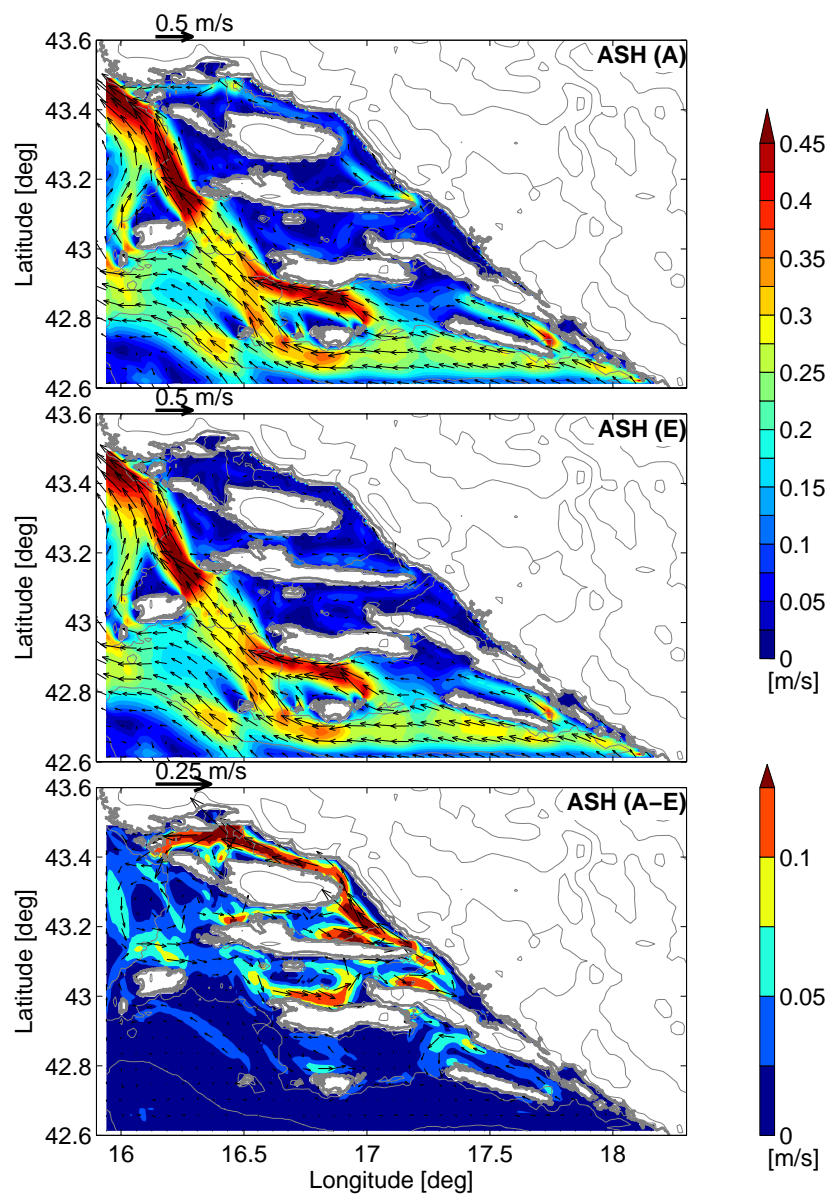

Fig. 8. Mean ASHELF-2 modeled vertically averaged currents for the Sirocco episode (Table 1) obtained with ALADIN and ECMWF forcing (top and center panels, respectively) and the differences between these two (bottom panel). Additionally, the magnitudes of vector differences $\mid$ ALADIN-ECMWF $\mid$ are shown in colors.

of the islands and the most prominent differences were found in the Brač channel. In the future, these coastal features should be better verified by in situ measurements, since it is well known that satellite SST data are less reliable in the vicinity of the coast. In addition, Sirocco events are generally accompanied with high cloudiness, especially close to the coast. This is due to forced convection of the warm and moist air along upstream topographical obstacles (islands and the mainland). Accordingly, the quality of satellite data in the vicinity of coast during Sirocco is additionally deteriorated.

The patterns of surface salinity fields for both forcings are also quite similar (Fig. 9, right panel), although ALADINforced surface salinities are slightly higher. The differences between the two experiments varied from 0 psu up to approximately $0.875 \mathrm{psu}$, and they are most pronounced in the narrow along-coast stripe stretching from the Neretva estuary towards the Brač channel. 


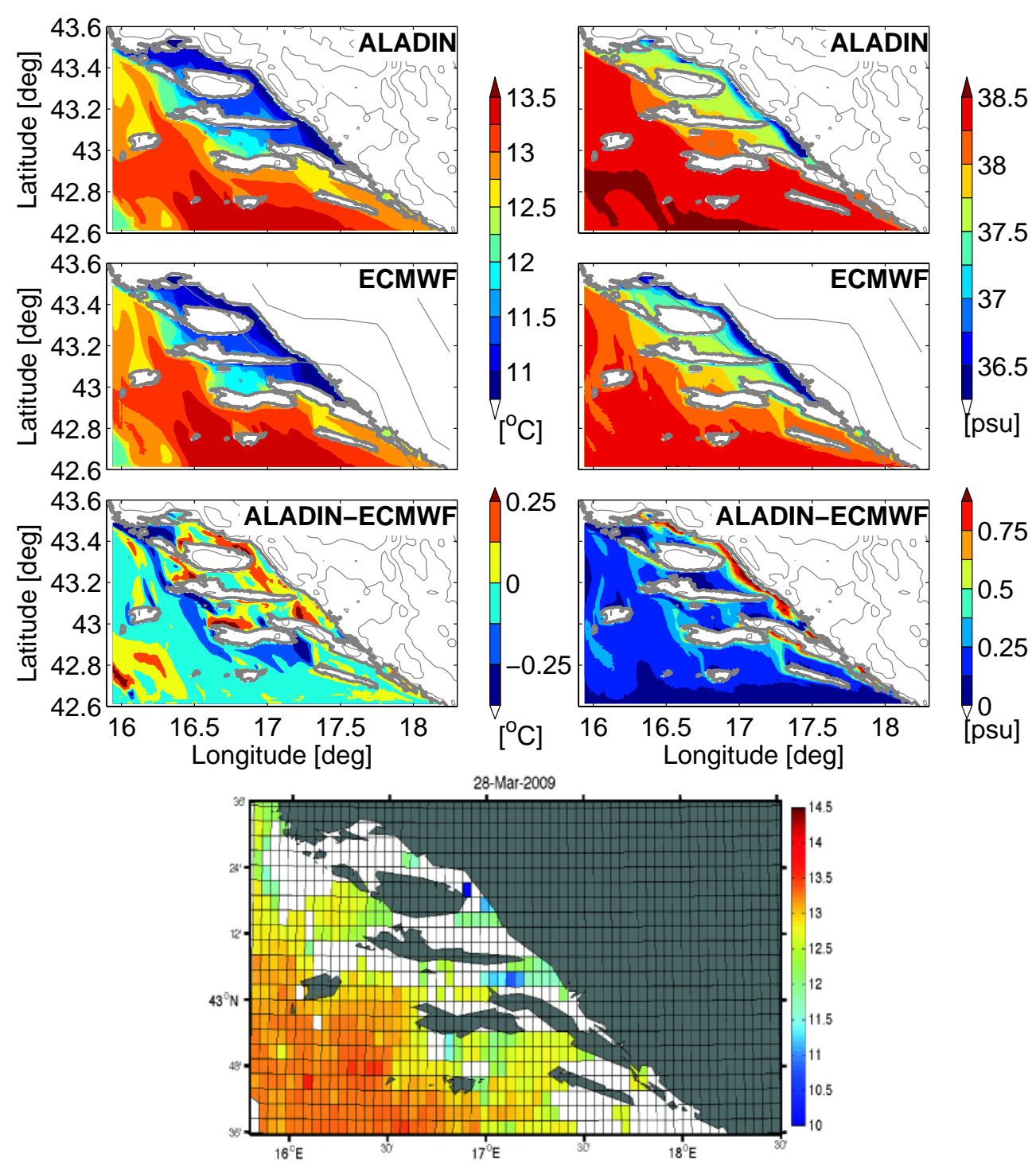

Fig. 9. Mean ASHELF-2 modeled sea surface temperatures (left panels) and surface salinities (right panels) for the Sirocco period (Table 1) obtained with ALADIN (top panels) and ECMWF (second from above) forcing and the differences between these two (third from above). The lowermost panel shows the satellite-measured sea surface temperature for 28 March 2009.

\section{Summary and conclusions}

We investigated the impact of atmospheric model resolution on the coastal sea's response to strong multi-day Bora and Sirocco episodes over the eastern coast of the middle Adriatic. The oceanographic modeling system (ASHELF-2) is based on the Princeton Ocean Model (POM) (Blumberg and Mellor, 1987), and it was implemented with $1 \mathrm{~km}$ horizontal resolution and $16 \sigma$ vertical layers. To account for the different atmospheric forcings, the ASHELF-2 surface fluxes were interactively computed using atmospheric fields obtained by two different models and the ASHELF-2 modeled sea surface temperature. Atmospheric forcing was produced by two models: ECMWF with a horizontal and temporal resolution of $0.25^{\circ}$ and $6 \mathrm{~h}$, respectively, and ALADIN with horizontal and temporal resolutions of $8 \mathrm{~km}$ and $3 \mathrm{~h}$, respectively. Both investigated wind episodes were of comparable strength and had a modeled average pseudo-stress up to approximately $110 \mathrm{~m}^{2} \mathrm{~s}^{-2}$ (Bora) and $130 \mathrm{~m}^{2} \mathrm{~s}^{-2}$ (Sirocco).

For both winds, the maximum differences in the modeled mean pseudo-stresses obtained by the fine and coarse resolution atmospheric forcing were of comparable magnitude; however, for Bora, they were slightly higher (about $60 \mathrm{~m}^{2} \mathrm{~s}^{-2}$ ) than for Sirocco (about $50 \mathrm{~m}^{2} \mathrm{~s}^{-2}$ ).

Using fine-resolution atmospheric forcing, a prominent, along-coast northwestward surface current in the Brač channel was found in both the Bora (maximum above $0.4 \mathrm{~m} \mathrm{~s}^{-1}$ ) and Sirocco (maximum approximately $0.6 \mathrm{~m} \mathrm{~s}^{-1}$ ) episodes. 
This current, which was not reproduced by the ocean model forced by coarse atmospheric model resolution, agrees with recent measurements that showed a strong, along-coast flow in the Brač channel during the wintertime (Andročec et al., 2009). For both episodes, the current maximum coincided with the maximum in the wind field.

Specifically, for the Bora episode, a noticeable, funnelshaped region of weak surface currents stretching from the coast towards the open sea in a southwestward direction was found for the fine resolution atmospheric forcing. This region of weak currents arose due to the orographically induced airflow splitting over the mainland and was further supported by the islands acting as obstacles to both the airflow and the sea currents.

For the Sirocco episode, the open-sea surface currents were very similar for both atmospheric forcings. However, the ECMWF-forced currents were somewhat stronger than the ALADIN-forced currents. In the coastal regions, the differences were most pronounced on the lee sides of inner islands, where ECMWF-forced surface currents were up to approximately $0.2 \mathrm{~m} \mathrm{~s}^{-1}$ higher than those forced by ALADIN.

The impact of the atmospheric model resolution on the modeled mass transport was most pronounced in the coastal areas for both Bora and Sirocco winds. For Sirocco, the ECMWF forcing resulted in almost no transport in the coastal regions, whereas the ALADIN forcing produced noticeable transports in limited coastal areas, which coincided with local wind maximums. For Bora, the ECMWF forced mass transport in coastal regions was weak, whereas it was substantially higher in the open sea. Conversely, the ALADIN-forced coastal and open-sea transports were generally comparable, and the northwestward transport in the Brač channel was the highest.

The different resolutions of the atmospheric forcings produced substantially larger differences in the SST and surface salinity fields in the case of the Bora forcing compared to the Sirocco episode. Therefore, the range of differences between the ALADIN- and ECMWF-forced SST for Bora was more than 3 times wider than the difference range for Sirocco. In the case of surface salinity, it was 1.5 times wider. Moreover, the patterns of the difference fields for SST and surface salinity for Bora were similar, and they resembled the patterns found in the pseudo-stress difference field, with the highest differences coinciding with the orographically induced, funnel-shaped region of weak winds. Comparison of the modeled and satellite-measured SST indicates more resemblance in the case of the ALADIN forcing, particularly in the area off the southern and western coasts of the Hvar and Korčula Islands. This result points to the ALADIN as a more reliable forcing in case of Bora wind. On the other hand, both forcings for Sirocco resulted in similar SST and surface salinity fields, which exhibited an almost uniform increase of SST and salinity in the offshore direction. Since the differences between the ALADIN- and ECMWF-forced SST are close to the accuracy of the satellite measurements it is hard to conclude which thermal forcing is better in the case of Sirocco.

To briefly summarize, we found that the atmospheric model resolution generally plays a more important role in the modeled coastal sea's response to the Bora forcing compared to the Sirocco forcing. This result can be attributed to the complicated, fine-scale atmospheric forcing that is produced when the Bora flow passes above the orographically complex mainland and islands and alternates with the sea surfaces. However, the modeled Sirocco-induced currents on the lee sides of the channels between the islands were also sensitive to the atmospheric model resolution.

We emphasize that our findings should be further corroborated by analyses of measured oceanographic data. In particular, this applies to the current-meter data, which were not available for the investigated period. Nevertheless, the results presented here indicate in which direction future investigations should be aimed. Finally, although the presented results were obtained for the eastern coast of middle Adriatic, they might also be useful in other coastal areas where complex orography plays a major role in atmospheric forcing.

Acknowledgements. This study was supported by the ECOOP project, which is funded by the European Commission's Sixth Framework Programme (contract 36355). Additional support was received through Ministry of Science, Education and Sports of the Republic of Croatia project grant nos. 119-1193086-1323, 119-1193086-3085, 001-0013077-1118 and 001-0013077-1122.

Edited by: S. Cailleau

\section{References}

Andročec, V., Beg Paklar, G., Dadić, V., Djakovac, T., Grbec, B., Janeković, I., Krstulović, N., Kušpilić, G., Leder, N., Lončar, G., Marasović, I., Precali, R., and Šolić, M.: The Adriatic Sea Monitoring Program - Final Report, MZOPUG, Zagreb, 2009.

Bajić, A.: Cold outbreak and the Adriatic bora, Geofizika, 4, 27-34, 1987.

Beg Paklar, G., Isakov, V., Koračin, D., Kourafalou, V., and Orlić, M.: A case study of Bora-driven flow and density changes on the Adriatic shelf (January 1987), Cont. Shelf Res., 21, 1751-1783, 2001.

Beg Paklar, G., Bajić, A., Dadić, V., Grbec, B., and Orlić, M.: Bora-induced currents corresponding to different synoptic conditions above the Adriatic, Ann. Geophys., 23, 1083-1091, doi:10.5194/angeo-23-1083-2005, 2005.

Belušić, D. and Klaić, Z. B.: Mesoscale dynamics, structure and predictability of a severe Adriatic Bora case, Meteorol. Z., 15, 157-168, 2006.

Blumberg, A. F. and Mellor, G. L.: A description of a three-dimensional coastal ocean circulation model, in: Threedimensional Coastal Ocean Models, edited by: Heaps, N. S., AGU, Washington, 1-16, 1987. 
Chiggiato, J. and Oddo, P.: Operational ocean models in the Adriatic Sea: a skill assessment, Ocean Sci., 4, 61-71, doi:10.5194/os-4-61-2008, 2008.

DHMZ: Meteorološki i hidrološki bilteni 2/2009-7/2009, DHMZ, Zagreb, 2009.

Ferrarese, S., Cassardo, C., Elmi, A., Genovese, R., Longhetto, A., Manfrin, M., and Richiardone, R.: Air-sea interactions in the Adriatic basin: simulations of Bora and Sirocco wind events, Geofizika, 26, 157-170, 2009.

Geleyn, J. F., Banciu, D., Bubnova, R., Ihasz, I., Ivanovici, V., Le Moigne, P., and Radnoti, G.: The international project ALADIN: Summary of events October 1992-October 1993, LAM Newsletter, 23, 1992.

Grubišić, V.: Bora-driven potential vorticity banners over the Adriatic, Q. J. Roy. Meteorol. Soc., 130, 2571-2603, 2004.

Heimann, D.: Model-based wind climatology of the eastern Adriatic coast, Meteorol. Z., 10, 5-16, 2001.

Hellerman, S. and Rosenstein, M.: Normal monthly wind stress over the world ocean with error estimates, J. Phys. Ocean., 13, 1093-1104, 1983.

Ivatek-Šahdan, S. and Tudor, M.: Use of high-resolution dynamical adaptation in operational suite and research impact studies, Meteorol. Z., 13, 99-108, 2004.

Janeković, I., Dutour Sikirić, M., Tomažić, I., and Kuzmić, M.: Hindcasting the Adriatic Sea surface temperature and salinity: A recent modeling experience, Geofizika, 27, 85-100, 2010.

Jurčec V., Ivančan-Picek, B., Tutiš, V., and Vukičević, V: Severe Adriatic jugo wind, Meteorol. Z., 5, 67-75, 1996.

Klaić, Z., Belušić, D., Grubišić, V., Gabela, L., and Ćoso, L.: Mesoscale airflow structure over the northern Croatian coast during MAP IOP 15 - a major Bora event, Geofizika, 20, 23-61, 2003.

Klaić, Z. B., Prodanov, A. D., and Belušić, D.: Wind measurements in Senj-underestimation of true Bora flows, Geofizika, 26, 245252, 2009a.

Klaić, Z. B., Pasarić, Z., and Tudor, M.: On the interplay between sea-land breezes and Etesian winds over the Adriatic, J. Mar. Syst., 78, S101-S118, doi:10.1016/j.jmarsys.2009.01.016, 2009b.

Kondo, J.: Air-sea bulk transfer coefficients in diabatic conditions, Bound.-Lay. Meteorol., 9, 91-112, 1975.

Makjanić, B: On the diurnal variation of the Bora wind speed, $\mathrm{Pa}-$ pers, 349, Yugoslav Academy of Sciences and Arts, Zagreb, 33 92, 1970.

Makjanić, B.: A short account of the climate of the town Senj, in: Local wind Bora, edited by: Yoshino, M. M., University of Tokio Press, 145-152, 1976.

May, P. W.: A brief explanation of Mediterranean heat and momentum flux calculations, NORDA Code 332, Naval Oceanographic and Atmospheric Research LaBoratory, Stennis Space Center, Mississippi, 5 pp., 1986.
Oddo, P., Pinardi, N., Zavatarelli, M., and Coluccelli, A.: The Adriatic basin forecasting system, Acta Adriat, 47(Suppl.), 169-184, 2006.

Orlić, M., Kuzmić, M., and Pasarić, Z.: Response of the Adriatic Sea to the Bora and Sirocco forcing, Cont. Shelf Res., 14, 91116, 1994.

Orlić, M., Beg Paklar, G., Pasarić, Z., Grbec, B., and Pasarić, M.: Nested modeling of the east Adriatic coastal waters, Acta Adriat., 47(Suppl.), 219-245, 2006.

Pasarić, M.: Annual cycle of river discharge along the Adriatic coast of Croatia, Rapports et proces-verbaux des reunions CIESMM 37, 132, CIESM, Monaco, 2004.

Pasarić, M. and Orlić, M.: Meteorological forcing of the Adriatic: present vs. projected climate conditions, Geofizika, 21, 69-87, 2004.

Pasarić, Z., Belušić, D., and Klaić, Z. B.: Orographic influences on the Adriatic sirocco wind, Ann. Geophys., 25, 1263-1267, doi:10.5194/angeo-25-1263-2007, 2007.

Pasarić, Z., Belušić, D., and Chiggiato, J.: Orographic effects on meteorological fields over the Adriatic from different models, J. Mar. Syst., 78, S90-S100, doi:10.1016/j.jmarsys.2009.01.019, 2009.

Pinardi, N., Allen, I., Demirov, E., De Mey, P., Korres, G., Lascaratos, A., Le Traon, P.-Y., Maillard, C., Manzella, G., and Tziavos, C.: The Mediterranean ocean forecasting system: first phase of implementation (1998-2001), Ann. Geophys., 21, 3-20, doi:10.5194/angeo-21-3-2003, 2003.

Pullen, J., Doyle, J. D., Hodur, R., Ogston, A., Book, J. W., Perkins, H., and Signell, R.: Coupled ocean-atmosphere nested modeling of the Adriatic Sea during winter and spring 2001, J. Geophys. Res., 108(C10), 3320, doi:10.1029/2003JC001780, 2003.

Radnóti, G.: Comments on "A Spectral Limited-Area Formulation with Time-Dependent Boundary Conditions Applied to the Shallow-Water Equations", Mon. Weather Rev., 123, 3122 3123, 1995.

Reed, R. K.: On estimating insolation over the ocean, J. Phys Ocean., 17, 854-871, 1977.

Signell, R. P., Carniel, S., Cavaleri, L., Chiggiato, J., Doyle, J. D., Pullen, J., and Sclavo, M.: Assessment of wind quality for oceanographic modelling in semi-enclosed basins, J. Mar. Syst., 53, 217-233, doi:10.1016/j.jmarsys.2004.03.006, 2005.

Zampato, L., Umgiesser, G., and Zecchetto, S.: Sea level forecasting in Venice through high resolution meteorological fields, Estuar. Coast. Shelf S., 75, 223-235, 2007.

Zavatarelli, M. and Pinardi, N.: The Adriatic Sea modelling system: a nested approach, Ann. Geophys., 21, 345-364, doi:10.5194/angeo-21-345-2003, 2003. 